\title{
Trabalho docente e valorização do magistério na rede municipal de São Paulo
}

\author{
Lisete Regina Gomes Arelaro ${ }^{1}$ \\ liselaro@usp.br \\ Márcia Aparecida Jacomini \\ marciajacomini@uol.com.br \\ Nilson Alves de Souza ${ }^{3}$ \\ pedagogia31@yahoo.com.br \\ Kátia Aparecida dos Santos ${ }^{4}$ \\ katcabre@yahoo.com.br
}

\begin{abstract}
Resumo
A partir dos anos de 1990, estados e municípios passaram a elaborar ou a adequar os planos de carreira, cargos e salários dos profissionais do magistério, frente às novas legislações. Esse movimento pode ser entendido como parte do atendimento, mesmo que parcial, a reivindicações históricas dos educadores e da compreensão de que a qualidade da educação está, também, vinculada à carreira e aos salários dos profissionais da educação. Neste texto, são analisados os aspectos referentes às formas de ingresso, composição da jornada de trabalho, progressão na carreira e composição da remuneração de acordo com a Lei n. 14.660/2007, que reorganiza o Quadro dos Profissionais de
\end{abstract}

1 Doutora em Educação pela Universidade do Estado de São Paulo, Brasil (1988). Professora da Faculdade de Educação da USP.

2 Doutora em Educação pela Universidade do Estado de São Paulo, Brasil (2008). Professora da Universidade Federal de São Paulo.

3 Mestrando em Educação pela Universidade do Estado de São Paulo, Brasil (2009).

4 Mestre em Educação pela Universidade do Estado de São Paulo, Brasil (2007). Professora da Rede

Municipal de Ensino de São Paulo. 
Educação do Município de São Paulo.

Palavras-chave: valorização do magistério; plano de carreira; jornada de trabalho docente; remuneração docente.

\section{Introdução}

A partir da década de 1990, com base na Constituição Federal de 1988 (CF / 88), na Lei de Diretrizes e Bases da Educação Nacional - Lei n. ${ }^{\circ}$ 9.394/1996 (LDB/96) -, na Emenda Constitucional n. 14/1996 (EC 14/06) e na Lei n. 9.424/1996, que regulamentou o Fundo de Manutenção e Desenvolvimento do Ensino Fundamental e de Valorização do Magistério (Fundef), estados e municípios passaram a elaborar planos de cargos, carreira e salários para os profissionais do magistério ou adequar os planos já existentes à legislação e às novas concepções de carreira docente que se conformaram no marco da reforma do Estado (Emenda Constitucional n. 19/1998).

Esse movimento pode ser entendido como parte do atendimento, mesmo que parcial, a reivindicações históricas dos educadores, e da compreensão de que a qualidade da educação tem relação com a carreira e os salários dos seus profissionais e da incorporação da avaliação de desempenho para progressão $0^{5}$ funcional, dado que, nas carreiras tradicionais, prevaleciam a titulação e o tempo de serviço (MORDUCHOWICZ, 2003).

Nesse contexto, o Ministério da Educação (MEC), por meio do FUNDESCOLA, publicou o documento "Plano de Carreira e Remuneração do Magistério Público: LDB, FUNDEF, Diretrizes Nacionais e nova concepção de carreira", no qual explicitou o marco legal que deveria servir de parâmetro para a construção dos planos dos profissionais da educação nos estados e municípios (DUTRA JÚNIOR et al., 2000).

Diferentemente da maioria dos municípios brasileiros, que só recentemente têm construído seus planos de carreira (GATTI; BARRETO, 2009), na rede municipal de ensino de São Paulo há legislação que regulamenta a vida profissional do professor desde 1967, quando foi

5 Neste texto, a palavra progressão será usada como termo genérico que indica a movimentação ou mobilidade ascendente na carreira. 
instituída a carreira do professor primário. No entanto, foi somente em 1992 que os professores obtiveram um Estatuto do Magistério. Considerado uma conquista da categoria docente, o Estatuto do Magistério Público Municipal de São Paulo (Lei n. 11.229/1992), aprovado na gestão da prefeita Luiza Erundina de Sousa (1989/92), sofreu duas importantes modificações, em atendimento às legislações posteriores e às concepções dos governos municipais subsequentes. A primeira foi realizada em 1993, por meio da Lei n. 11.434, no governo Paulo Maluf (1993/96), e a segunda, em 2007, por meio da Lei n. 14.660, nas administrações Gilberto Kassab I e II (2006/08 e 2009/12).

De acordo com o documento do FUNDESCOLA/MEC, o estatuto diz respeito a um conjunto de normas que regulamenta a relação do servidor público com o Estado. Ele contempla o regime jurídico único e trata da investidura no cargo, dos direitos, deveres e das responsabilidades do servidor (DUTRA JÚNIOR et al., 2000). Nesses termos, a Lei n. 11.229/1992, que trata do Estatuto dos Profissionais do Magistério, compreende aqueles que desempenham atividades de docência ou de suporte pedagógico à docência: coordenador pedagógico, diretor de escola e supervisor escolar (SÃO PAULO, 1992).

A Lei n. 11.434/1993, diferentemente do Estatuto de 1992, dispunha sobre a organização dos Quadros ${ }^{6}$ dos Profissionais da Educação, criava novas escalas de vencimentos e instituía planos de carreiras para os Quadros do Magistério e de Apoio à Educação. Essa lei, ao instituir o Quadro dos Profissionais de Educação, incluiu todos os profissionais da escola e de órgãos centrais e intermediários na educação (SÃO PAULO, 1993). A Lei n. 14.660/2007 modificou as duas anteriores, reorganizando o Quadro dos Profissionais de Educação e respectivas carreiras criadas pela Lei de 1993, e consolidou o Estatuto do Magistério Público do Município de São Paulo (SÃO PAULO, 2007).

Ainda de acordo com o documento do MEC/FUNDESCOLA, plano de carreira refere-se a um conjunto de normas que define a condição de progressão na carreira:

6 "Quadro será entendido como o conjunto de carreiras, cargos isolados (incluem os cargos em comissão) e funções gratificadas de um mesmo serviço, órgão ou poder". (DUTRA JÚNIOR et al., 2000, p. 204). 
O plano de carreira é instrumento de administração de recursos humanos voltado essencialmente para a profissionalização. Nessa condição, considera, de forma especial, algumas variáveis essenciais à sua finalidade, quais sejam, o desempenho do servidor no exercício de suas atribuições, os programas de desenvolvimento de recursos humanos, a estrutura de classes e o sistema de remuneração. (DUTRA JÚNIOR et al., 2000, p. 204).

Em estudo sobre a carreira docente em países da América Latina, Morduchowicz (2003) constatou que a antiguidade ainda é um dos principais incentivos de progressão dentro da carreira do magistério:

As escolas estão entre as organizações em que: (a) a antiguidade segue sendo um dos principais incentivos; (b) as promoções implicam deixar o trabalho que se vinha desenvolvendo e, mais ainda, (c) as promoções dependem das aposentadorias dos ocupantes de postos superiores na escala hierárquica. (MORDUCHOWICZ, 2003, p. 10).

No entanto, as propostas de avaliação de desempenho têm conquistado espaço no cenário latino-americano e se apresentam, no discurso de governos e setores que defendem a utilização de critérios afeitos às empresas no setor educacional público, como uma necessidade para melhorar a qualidade das escolas:

$\mathrm{Na}$ verdade, o pagamento generalizado e homogêneo atendia às necessidades e ao contexto que imperava na época em que foi desenhado. [...] os novos enfoques sobre o tema remetem à busca de um esquema capaz de superar os mecanismos tradicionais de remuneração que, em sua maior parte, encontra-se em franca decadência por não se vincularem às necessidades organizacionais e aos processos de trabalho exigidos para o desenvolvimento de escolas eficazes. (MORDUCHOWICZ, 2003, p. 10-11).

A legislação brasileira referente aos planos de carreira dos profissionais da educação, desde a LDB/96, tem contemplado a avaliação de desempenho como um dos requisitos para a progressão na carreira. 
Entretanto, a forma como a avaliação de desempenho consta dos planos e o peso que ela representa na carreira parecem estar diretamente vinculados às concepções dos gestores municipais e estaduais, isto é, se defendem que os salários sejam vinculados à avaliação de desempenho dos alunos ou a avaliações dos professores, às negociações com os sindicatos e à mobilização dos profissionais do magistério.

A rede municipal de São Paulo está entre as maiores redes de ensino do país, com cerca de um milhão de alunos e mais de cinquenta mil professores em 2010. Na rede municipal de São Paulo existem, também, quatro sindicatos que atuam na defesa dos trabalhadores em educação: Sindicato dos Profissionais em Educação no Ensino Municipal de São Paulo (Sinpeem), Sindicato de Professores e Funcionários Municipais de São Paulo (Aprofem), Sindicato dos Trabalhadores nas Unidades de Educação Infantil da Rede Municipal de São Paulo (Sedin) e Sindicato dos Especialistas de Educação do Ensino Público Municipal de São Paulo (Sinesp).

Com o objetivo de compreender o plano de carreira do magistério da cidade de São Paulo, no marco da legislação recente e das novas concepções de carreira, serão analisadas a forma de ingresso, a composição da jornada de trabalho, a progressão na carreira e a composição da remuneração com base na Lei n. 14.660/2007.

\section{Ingresso na carreira docente}

De acordo com a Lei n. 14.660/2007, o quadro dos profissionais da educação é composto por cargos de provimento efetivo e em comissão 7 . A efetivação no cargo dar-se-á após os três anos de estágio probatório, conforme disposto na EC n. 19/98 (BRASIL, 1998). O ingresso na carreira para a classe de docentes ocorre mediante concurso público de provas e títulos. Estão previstas duas classes no quadro dos profissionais de educação: (1) a classe dos docentes, que compreende os cargos de Professor de Educação Infantil, de Professor de Educação Infantil e Ensino Fundamental I e de Professor de Ensino Fundamental II e Médio

7 Cargo em Comissão só admite provimento em caráter provisório. Os cargos são permanentes, mas a permanência no cargo é sempre precária, pois quem o exerce não adquire direito de continuar no cargo (DUTRA JÚNIOR et al., 2000). 
e (2) a classe dos gestores educacionais, composta pelos cargos de Coordenador Pedagógico, de Diretor de Escola e de Supervisor Escolar ${ }^{8}$ (SÃO PAULO, 2007).

O ingresso na carreira do magistério, por meio de concurso público, está previsto na $\mathrm{CF} / 88$ e na $\mathrm{LDB} / 96$ e faz parte das reivindicações dos sindicatos de professores. A defesa do concurso público contrapõe-se às práticas de indicação (clientelismo/apadrinhamento) por políticos que buscam compor sua base de apoio, utilizando-se do emprego no serviço público.

Além de combater as práticas clientelistas, o concurso público para o ingresso na carreira do magistério visa assegurar a impessoalidade e a transparência no processo de escolha dos profissionais com melhor preparo para o exercício da profissão, dentro dos requisitos que os concursos conseguem aferir.

Apesar do art. 85 da LDB/96 estabelecer o dever do poder público de realizar concurso periodicamente (BRASIL, 1996), ainda há redes de ensino em que o contingente de professores contratados temporariamente chega a representar $50 \%$ dos docentes.

Na rede municipal de São Paulo, a maioria dos professores é concursada. De acordo com dados obtidos junto à Secretaria Municipal de Educação, em 2010, dos 56.872 profissionais do magistério da rede municipal de ensino de São Paulo, 50.676 (89,1\%) eram efetivos. Desde 1992, quando o Estatuto do Magistério estabeleceu, no $\S 1^{\circ}$ do art. $7^{\circ}$, que os concursos públicos deveriam ser realizados a cada dois anos ou quando o percentual de cargos vagos atingisse $5 \%$ do total de cargos da respectiva área, a administração pública municipal tem realizado concursos regularmente (SÃO PAULO, 1992). Entretanto, a Lei n. $14.660 / 2007$, em seu art. $9^{\circ}$, retirou a periodicidade, mantendo a realização de concursos quando o percentual dos cargos vagos atingirem

8 Na década de 1980, somente os professores concursados da rede podiam prestar concurso para os cargos de diretor de escola e coordenador pedagógico. O cargo de supervisor escolar era provido por indicação do Secretario de Educação. Com a Lei n. 11.229/92 e a Lei n. 11.434/93, a carreira do magistério passou a ser aberta - para todos os cargos havia concurso de ingresso e acesso, inclusive para supervisor de ensino, cujo cargo foi criado em 1992 com provimento por concurso. Com a Lei n. 14.660/07, os cargos de coordenador pedagógico, diretor de escola e supervisor escolar passam a ser providos somente por concurso de acesso, fechando novamente a carreira. 
$5 \%$ do total de cargos da classe ou quando não houver concursados excedentes do concurso anterior (SÃO PAULO, 2007).

Além dos professores concursados há, ainda, aqueles que ganharam estabilidade no serviço público de acordo com o art. 19 do Ato das Disposições Constitucionais Transitórias da CF/88, que considerou estáveis os servidores públicos civis da União, dos estados, do Distrito Federal e dos municípios. Esses servidores contavam com, pelo menos, cinco anos de serviço público, na data da promulgação do referido Ato (BRASIL, 1988).

A rede conta, ainda, com professores que são contratados por meio de um contrato temporário de trabalho pelo prazo máximo de doze meses, podendo ser renovado por igual período, conforme prevê o art. 108 da Lei n. 14.660/2007 (SÃO PAULO, 2007).

Todo profissional do Quadro, atendendo ao disposto na EC n. 19/98, passará por um período de estágio probatório de três anos de efetivo exercício, que se segue ao início no cargo de provimento efetivo na carreira. Após esse período, o servidor será submetido a uma avaliação especial de desempenho para adquirir a estabilidade. Além disso, o § $4^{\mathrm{o}}$ do art. 33 da Lei n. 14.660/2007 dispõe que “o servidor que após o cumprimento do estágio probatório não adquirir a estabilidade será exonerado" (SÃO PAULO, 2007).

\section{Jornada de trabalho docente e qualidade do ensino}

A definição de uma jornada de trabalho compatível com a especificidade do trabalho docente está diretamente relacionada à valorização do magistério e à qualidade do ensino, uma vez que a dupla ou tripla jornadas comprometem o desempenho do professor.

Ao discutir a valorização salarial dos professores do ensino público, Monlevade (2000) alerta para a relação entre desvalorização salarial e aumento da jornada de trabalho no magistério público:

Premida pela demanda de novos alunos, ou espremida pelo baixo salário, a professora duplicou e até triplicou sua jornada de trabalho na escola. Se fosse professora particular nos dois turnos, certamente 
teria dobrado o salário. No caso das professoras de redes públicas, a tendência foi outra: mais turnos e horas de trabalho e o salário proporcionalmente menor. No caso de uma combinação de patrões diferentes - públicos federal, estadual e municipal e privados ou comunitários - os ganhos e perdas salariais com a multiplicação de turnos podiam ser e realmente foram os mais diversos. O que importa é a tendência à sobrecarga do trabalho direto com a desvalorização salarial e a desqualificação da profissão. (MONLEVADE, 2000, p. 70).

As discussões mais recentes sobre jornada têm reafirmado a necessidade de o professor ter uma única jornada e trabalhar somente numa escola, o que garantirá melhores condições de trabalho. Respeitando a diversidade e a especificidade das redes de ensino, a Resolução CNE/ CEB n. 2/2009 propõe que as redes de ensino façam esforços no sentido de avançar rumo à jornada integral de 40 horas/semanais, com a vinculação do professor a uma única escola (BRASIL, 2009).

Tomando como referência os anos de 1990, as discussões reforçam o disposto na LDB/96 sobre a necessidade da jornada de trabalho docente ser composta por um percentual de horas destinadas às atividades de preparação de aula, correção de atividades, atendimento aos pais, formação continuada, desenvolvimento de trabalho coletivo na escola, dentre outras atividades inerentes ao trabalho do professor.

Na rede municipal de ensino da cidade de São Paulo, há dois tipos de jornadas de trabalho para os docentes: as Jornadas Básicas e as Jornadas Especiais de Trabalho. As Jornadas Básicas realizam-se de duas formas: 1- Jornada Básica de 30 horas semanais de trabalho (J-30), para o cargo de professor da educação infantil, cumprida exclusivamente nos Centros de Educação Infantil (CEIs) ${ }^{9}$. Ela é composta por vinte e cinco horas em regência de turma e cinco horas/atividades. Dessas, três horas são de trabalho coletivo e duas horas de trabalho individual, cumpridas na escola. 2- Jornada Básica do Docente (JBD), de 30 horas/aula de trabalho semanal (22 horas e 30 minutos), destinada ao cargo de professor de

9 CEI referem-se às antigas creches que foram transferidas da Secretaria Municipal da Cidadania e Bem Estar Social para a Secretaria de Educação. 
educação infantil e ensino fundamental I e ao cargo de professor de ensino fundamental II e médio. Nessa jornada, cinco horas/aula são reservadas para atividade extraclasse, sendo três cumpridas, obrigatoriamente, na escola e duas em local de livre escolha ${ }^{10}$. Observe-se que, para o professor que trabalha nos CEI, a jornada é definida por hora relógio (60 min.) e para as demais jornadas a hora aula corresponde a 45 minutos.

As Jornadas Especiais de Trabalho compreendem: 1- Jornada Especial Integral de Formação (JEIF), composta por 25 horas aula em regência de classe e 15 horas aula adicionais (30 horas). Os professores de educação infantil e ensino fundamental I e de ensino fundamental II e médio podem solicitar, anualmente, o ingresso nessa jornada, porém ele só será autorizado se o professor estiver em regência de classe.

De acordo com o plano de carreira atual, a hora/atividade, definida como o tempo que o docente dispõe para atividade extraclasse, compreende: reuniões pedagógicas, preparação de aulas, pesquisas, seleção de material pedagógico e correção de avaliações. Além das atividades descritas, o docente em JEIF, deverá realizar atividades com a comunidade, pais e alunos, exceto as de reforço, recuperação de alunos e reposição de aulas. Do total de 15 horas aula adicionais, onze serão cumpridas, obrigatoriamente, na escola, das quais oito de trabalho coletivo e as quatro restantes em local de livre escolha. 2 - Jornada Especial de Trabalho Excedente (TEX) e Jornada Especial de Horas Aula Excedentes (JEX). Horas de trabalho excedentes são aquelas que excedem a carga horária regular do professor e são destinadas à participação em Projetos Especiais de Ação ${ }^{11}$ (PEAs), quando relativas à TEX, ou às horas aula ministradas pelo professor, quando relativas à JEX. De acordo com as necessidades da escola, o diretor poderá atribuir, mediante anuência do profissional, horas excedentes que compõem essas duas jornadas para os professores de educação infantil e ensino fundamental I e ensino fundamental II e médio. Aos professores de educação infantil somente

10 A Lei n. 14.660/2007 extinguiu a Jornada Básica (JB) de 20 horas aulas. Sendo assim, a JB entra em vacância, restando apenas alguns servidores nessa jornada.

12 Segundo a Portaria n. 1566/2008, “Art. $1^{\circ}$ - Os Projetos Especiais de Ação - PEAs são instrumentos de trabalho elaborados pelas Unidades Educacionais, que expressam as prioridades estabelecidas no Projeto Pedagógico, voltadas essencialmente às necessidades dos educandos, definindo as ações a serem desencadeadas, as responsabilidades na sua execução e avaliação, visando ao aprimoramento das práticas educativas e consequente melhoria da qualidade de ensino [...]." (SÃO PAULO, 2008a). 
podem ser atribuídas horas excedentes relativas à TEX.

A concepção da JEIF estava presente no Estatuto de 1992, na proposta de uma Jornada de Tempo Integral (JTI) de 30 (trinta) horas, quando, pela primeira vez, a rede municipal de ensino da cidade de São Paulo conquistou uma jornada de trabalho que destinava $1 / 3$ das horas da mesma às atividades extraclasse ${ }^{12}$.

A concepção de $1 / 3$ da jornada docente ser destinada a atividades extraclasse foi mantida nas leis subsequentes, embora sua denominação tenha mudado. No entanto, é necessário destacar que não tem sido destinada a mesma proporção de horas para atividades extraclasse em todas as jornadas e, no caso dos professores de educação infantil, que trabalham nos CEIs, a proporção de horas para atividades extraclasse é bem inferior a $1 / 3$, correspondendo a $1 / 6$ da jornada.

A proposta presente na Resolução CNE/CEB n. 2/2009 dos sistemas de ensino priorizarem a jornada de tempo integral, com o máximo de 40 horas, busca estabelecer uma jornada adequada, com vistas a evitar uma sobrecarga de trabalho que, inevitavelmente, afetaria a qualidade da atividade docente.

Na rede municipal de ensino de São Paulo, o profissional que acumula cargo deve fazer declaração anual, sendo-lhe facultado o acúmulo de dois cargos, totalizando até 70 horas semanais de trabalho. Não resta dúvida de que 70 horas semanais de trabalho são incompatíveis com um bom desempenho profissional e representam um absoluto desrespeito ao trabalhador. Tal absurdo somente pode ser compreendido no marco dos baixos salários que há tempos têm sido compensados com o aumento da jornada de trabalho. Por isso, constata-se certa pressão contraditória dos professores e do sindicato pela manutenção do direito ao acúmulo.

\section{Carreira e valorização profissional: promoção e evolução funcional}

A progressão na carreira é uma das questões mais debatidas entre governos e representantes dos servidores quando das negociações dos

12 A JTI atendia à composição da jornada, posteriormente proposta na Lei Federal n. 11.738/2008 que instituiu o piso salarial profissional para os profissionais do magistério público da educação básica. 
planos de carreira dos profissionais da educação pública. Dois aspectos principais polarizam o debate: (1) a dispersão salarial, que se refere à "distância entre a menor e a maior remuneração que correspondem, respectivamente, ao início e ao fim da carreira de uma determinada categoria profissional" (DUTRA JÚNIOR et al., 2000, p. 131) e (2) os critérios adotados para a progressão na carreira.

Embora haja diferenças na jornada de trabalho entre o cargo de Professor de Educação Infantil e os cargos de Professor de Educação Infantil e Ensino Fundamental I e Professor de Ensino Fundamental II e Médio, no plano de carreira da rede municipal de ensino da cidade de São Paulo, os critérios e formas para a evolução funcional e promoção são os mesmos entre os cargos mencionados.

Considera-se, nos termos do art. 20 da Lei n. 14.660/2007, como padrão de vencimentos o conjunto de referências e graus. As referências são posições na escala de padrões de vencimentos organizadas verticalmente. Na classe dos docentes, a primeira referência recebe o número 11, seguindo, sucessivamente, até o número 21 . Os graus, em número de cinco, compreendem as posições na escala de padrões de vencimentos da carreira organizados horizontalmente e representados por letras de A a E (SÃO PAULO, 2007).

No Estatuto de 1992, as referências e graus guardavam entre si diferenças equidistantes de 5\%. Em 1993, as diferenças passaram para $6,5 \%$, sendo mantidas na Lei de 2007 , permitindo, assim, uma dispersão salarial de aproximadamente $141 \%$, considerando da primeira referência e grau, condição para ingressantes com formação em ensino médio (modalidade normal), à última referência e último grau, com ensino superior. A TAB. 1 expressa de forma objetiva essa dispersão salarial: 
TABELA 1

Dispersão salarial

\begin{tabular}{c|c|c|c|c|c}
\hline Referência/Grau & A & B & C & D & D \\
\hline 11 & 100,0 & 106,5 & 113,4 & 120,8 & 128,6 \\
12 & 106,5 & 113,4 & 120,8 & 128,6 & 137,0 \\
13 & 113,4 & 120,8 & 128,6 & 137,0 & 145,9 \\
14 & 120,8 & 128,6 & 137,0 & 145,9 & 155,4 \\
15 & 128,6 & 137,0 & 145,9 & 155,4 & 165,5 \\
16 & 137,0 & 145,9 & 155,4 & 165,5 & 176,3 \\
17 & 145,9 & 155,4 & 165,5 & 176,3 & 187,7 \\
18 & 155,4 & 165,5 & 176,3 & 187,7 & 199,9 \\
19 & 165,5 & 176,3 & 187,7 & 199,9 & 212,9 \\
20 & 176,3 & 187,7 & 199,9 & 212,9 & 226,7 \\
21 & 187,7 & 199,9 & 212,9 & 226,7 & 241,5 \\
& & & & & \\
\hline
\end{tabular}

Fonte: Tabela elaborada pelos autores a partir da Lei n. 14.660/2007.

Nota: Nessa tabela, a referencia/grau inicial (11 A) corresponde a 100,0.

O professor movimenta-se na escala de padrões de vencimentos sempre em direção à condição superior à qual se encontrava anteriormente, de duas maneiras: (1) por Evolução Funcional, que corresponde à passagem de uma referência à outra, respeitados os critérios de tempo, de títulos ou a combinação de ambos, prevista no art. 35 da Lei n. 14.660/2007 e (2) por Promoção, prevista no art. 67 da Lei n. 8.989/1979 - Estatuto dos Funcionários Públicos do Município de São Paulo - como "a passagem do funcionário de um determinado grau para o imediatamente superior da mesma classe" (SÃO PAULO, 1979).

A promoção está prevista para todos os servidores municipais da cidade de São Paulo e tanto a evolução funcional como a promoção na carreira ocorrem de forma independente. Quando um docente atinge os critérios para a passagem de uma referência à outra, isto não implica alteração do grau ao qual ele se encontra, ainda que o professor possa ter evolução funcional e ser promovido, ao mesmo tempo, se tiver alcançado os critérios para ambas.

A promoção pode ocorrer por antiguidade e por merecimento. No caso da promoção por antiguidade, deve-se respeitar o interstício de três anos de efetivo exercício no grau. A promoção por merecimento requer 
dois anos de efetivo exercício no cargo e poderá ocorrer anualmente se o servidor tiver pontuação para tal. Do total dos funcionários de cada grau, em cada classe, $16 \%$ podem ser promovidos por antiguidade. A promoção por antiguidade ocorre em junho de cada ano e o período para efeito do seu processamento é sempre o ano civil anterior. A promoção por merecimento ocorre em dezembro e o período para efeito de seu processamento é o mesmo que o por antiguidade. De acordo com o art. 70 da Lei n. 8.989/1979:

Merecimento é a demonstração positiva do funcionário no exercício de seu cargo enquanto integrante de uma determinada classe e se evidencia pelo desempenho de forma eficaz e eficiente das atribuições que lhe são cometidas, bem como pelo seu aperfeiçoamento funcional resultante do aprimoramento de seus conhecimentos. (SÃO PAULO, 1979).

O desempenho é avaliado, no caso da classe docente, pela chefia imediata e por meio de autoavaliação, com base no tempo de serviço público, tempo de serviço no cargo e mérito, por meio de instrumento próprio e cursos realizados. Na aferição do desempenho são atribuídas pontuações para promoção a cada grau. Para a classe dos docentes, estão previstas duas categorias, definidas mediante a titulação acadêmica do professor, quais sejam: Categoria 1 - os docentes com habilitação específica em nível de ensino médio (normal ou magistério), somente para os Professores de Educação Infantil e os Professores de Educação Infantil e Ensino Fundamental I; e Categoria 3 - para os docentes com titulação de nível superior (licenciatura plena), para os Professores de Ensino Fundamental II e Ensino Médio. A TAB. 2 explicita as posições inicial e final, na escala de padrões de vencimentos por titulação, da classe de docentes. 
TABELA 2

Posição inicial e final na escala de padrões de vencimentos por titulação ${ }^{13}$

\begin{tabular}{|c|c|c|c|}
\hline \multirow[b]{2}{*}{ Titulação necessária } & Categoria 1 & Categoria 3 & \multirow{2}{*}{$\begin{array}{c}\text { Distância entre } \\
\text { as categorias } 1 \text { e } 3\end{array}$} \\
\hline & $\begin{array}{c}\text { Ensino Médio } \\
\text { Modalidade } \\
\text { Normal }\end{array}$ & $\begin{array}{c}\text { Ensino Superior } \\
\text { Licenciatura } \\
\text { Plena }\end{array}$ & \\
\hline $\begin{array}{l}\text { Posição inicial na } \\
\text { Escala de Padrões } \\
\text { de Vencimentos }\end{array}$ & $11 \mathrm{~A}$ & $14 \mathrm{~A}$ & $21 \%$ \\
\hline $\begin{array}{l}\text { Posição final na } \\
\text { Escala de Padrões } \\
\text { de Vencimentos }\end{array}$ & $18 \mathrm{E}$ & $21 \mathrm{E}$ & $21 \%$ \\
\hline
\end{tabular}

Fonte: Tabela elaborada pelos autores a partir da Lei n. 14.660/2007.

A escala de padrões de vencimentos, conforme mostra a TAB. 1, possui uma dispersão salarial de $141,5 \%$. No entanto, se considerarmos apenas a dispersão em cada categoria, ela é de aproximadamente $100 \%$, devido às posições inicial e final de cada categoria, conforme registrado na TAB. 2. A passagem de uma categoria a outra é nomeada, no plano de carreira, como enquadramento. O professor pode solicitar enquadramento na categoria 3, em qualquer momento da carreira, apresentando comprovante de licenciatura plena. Aqueles que por outros critérios (tempo, títulos ou a combinação dos dois) já tiverem alterado sua posição na escala de padrões de vencimentos terão acrescido o número de referências que há entre as categorias 1 e 3, ou seja, 3 referências. Por exemplo: um professor que ingressou com formação em nível médio (magistério), 11A, e que passou por duas evoluções funcionais, estando, portanto, na 13A, ao apresentar o diploma de conclusão de licenciatura plena será enquadrado em três referências superiores, atingindo a 16A. Quando ocorre enquadramento, não há alteração no grau em que o professor se encontra.

Pode-se afirmar que o enquadramento por categoria, na carreira de professores da prefeitura de São Paulo, traduz incentivo à titulação em

13 Em 2010, o valor do padrão de vencimento da referência 11A era de $\mathrm{R} \$ 1.063,69$ e da $14 \mathrm{~A}$, de $\mathrm{R} \$$ 1.284,93, para a Jornada Básica Docente (JBD) - 30 horas aula. 
licenciatura plena, pois sem essa titulação o professor não alcançará a última referência da carreira.

Em estudo sobre os professores brasileiros, Gatti e Barreto (2009) encontraram três categorias de titulação com salários diferenciados: nível médio (modalidade normal), graduação em nível superior e pósgraduação. No caso do município de São Paulo, a formação em pósgraduação (lato sensu, mestrado ou doutorado) não é considerada para fins de enquadramento. Essa formação é contabilizada como titulação acadêmica (com pontuação previamente estabelecida para cada título) para a soma da pontuação necessária à evolução funcional por titulação. Assim, se um professor da rede municipal de São Paulo se afastar, com interrupção da contagem do tempo no cargo, para fazer mestrado ou doutorado, por um período de três ou quatro anos, ao término do curso a pontuação que ele receberá por essa titulação, para efeitos de evolução funcional, será menor que a pontuação daqueles que permaneceram no exercício do cargo.

Se, por um lado, pode-se inferir que o plano de carreira da rede municipal de ensino de São Paulo incentiva a formação em nível superior, por outro não estimula a formação em pós-graduação.

No entanto, conforme prevê o inciso II do art. 53 da Lei n. 14.660/2007, os profissionais do quadro do magistério têm "assegurada a oportunidade de frequentar cursos de graduação, pós-graduação, atualização e especialização profissional, na forma estabelecida em regulamento" (SÃO PAULO, 2007). Afastamentos para essa finalidade, com ou sem remuneração, estão previstos, sendo prerrogativa da Administração autorizar os pedidos aos quais a Lei se refere. Como não houve regulamentação, até o final de 2010, os pedidos de afastamentos para estudo têm sido negados, levando o profissional a solicitar Licença para Tratar de Interesses Particulares (LIP), que, na prática, anula aquele direito.

É importante destacar que foi reivindicação da categoria de professores os cursos de especialização, mestrado e doutorado não serem considerados para enquadramento, mas como pontuação para evolução funcional. Considerou-se que, como poucos professores podem fazer esses cursos, a maioria não chegaria ao final da carreira, caso eles fossem considerados 
para enquadramento tal como o diploma de licenciatura plena.

A progressão na carreira, para os professores da rede municipal de ensino de São Paulo, está baseada em dois critérios: tempo e títulos. A evolução funcional do professor baseada no tempo de serviço no cargo ocorre de acordo com a periodicidade apresentada na TAB. 3:

TABELA 3

Interstício para evolução funcional

\begin{tabular}{c|c|c}
\hline \multirow{2}{*}{ Referência } & Categoria 1 & Categoria 2 \\
\cline { 2 - 3 } & Tempo & Tempo \\
\hline 11 & 0 & - \\
\hline 12 & 3 & - \\
\hline 13 & 5 & - \\
\hline 14 & 8 & 0 \\
\hline 15 & 12 & 3 \\
\hline 16 & 16 & 5 \\
\hline 17 & 20 & 8 \\
\hline 18 & 22 & 12 \\
\hline 19 & - & 16 \\
\hline 20 & - & 20 \\
\hline 21 & - & 22 \\
\hline
\end{tabular}

Fonte: Tabela elaborada pelos autores a partir da Lei n. 14.660/2007.

Pelo critério de tempo, o professor pode chegar ao final da carreira após 22 anos de exercício.

A evolução funcional baseada em títulos compreende: cursos de graduação, pós-graduação, especialização, cursos promovidos, reconhecidos ou patrocinados pelo órgão técnico da Secretaria Municipal de Educação e tempo de exercício no cargo. A esses elementos são atribuídos pontos, de acordo com tabela específica, para a mudança de referência.

Assim, a evolução funcional baseada em títulos será realizada de acordo com a participação em atividades de formação continuada, aprimoramento profissional e exercício no magistério. Além dos cursos 
realizados fora do horário de trabalho, também são computados, para evolução por títulos, a pontuação recebida por participação em projetos realizados na escola, a exemplo dos Projetos Especiais de Ação (PEAs), pela participação como membros de Conselho de Escola e Associação de Pais e Mestres e pela produção acadêmica, científica e cultural.

A evolução por título respeita o interstício mínimo de um ano na mesma referência, sendo que a primeira evolução funcional só poderá ser solicitada após o cumprimento dos três anos de período probatório. Esses títulos que o professor adquire pela participação em atividades de formação continuada, pela participação em projetos ou pela realização de cursos de pós-graduação permitem que ele tenha uma evolução funcional mais rápida, chegando ao final da carreira num período mais curto de tempo.

Para os professores que trabalharam na rede de ensino, em período anterior ao da efetivação no cargo (em caráter efetivo ou precário), é possível aproveitar esse tempo a partir da segunda evolução, aplicando tabela específica que combina os critérios para evolução por tempo e título.

Uma observação importante é que, embora a carreira não esteja calcada na avaliação de desempenho, o plano já contém um embrião do que poderá vir a ser um sistema de avaliação vinculado à remuneração, a depender de como será regulamentada a "Certificação de Valoração Profissional" (arts. 35 e 40). Essa não regulamentação, possivelmente, permanece pela pressão dos sindicatos que historicamente consideram esse critério um dos mais injustos para com os professores por não abranger suas condições de trabalho e ensino.

\section{Componentes da remuneração: vencimentos, gratificações e auxílios}

A remuneração dos professores da rede municipal de ensino de São Paulo é composta pelo vencimento ${ }^{14}$ e pelas vantagens pecuniárias estabelecidas em Lei. Assim, a remuneração é definida com base na jornada do professor, considerando o conjunto de grau e referência, de acordo com a progressão na carreira. Na TAB. 4 é apresentado o padrão

14 Vencimento "é a retribuição pecuniária pelo exercício do cargo público, com valor fixado [...]." (DUTRA JÚNIOR et al., 2000, p. 215). 
de vencimento referente aos cargos de professor na Jornada Básica do Docente (JBD), que corresponde à jornada de ingresso na carreira para professores que atuam na Educação Infantil (com crianças de 4 a 5 anos) e professores de Ensino fundamental I e II e Médio:

\section{TABELA 4}

Padrão de Vencimento referente aos cargos de professor na JBD

\begin{tabular}{c|c|c|c|c|c}
\hline Referência/Grau & A & B & C & D & E \\
\hline 11 & $\mathrm{R} \$ 1.063,69$ & $\mathrm{R} \$ 1.132,88$ & $\mathrm{R} \$ 1.206,50$ & $\mathrm{R} \$ 1.284,93$ & $\mathrm{R} \$ 1.368,44$ \\
12 & $\mathrm{R} \$ 1.132,88$ & $\mathrm{R} \$ 1.206,50$ & $\mathrm{R} \$ 1.284,93$ & $\mathrm{R} \$ 1.368,44$ & $\mathrm{R} \$ 1.457,38$ \\
13 & $\mathrm{R} \$ 1.206,50$ & $\mathrm{R} \$ 1.284,93$ & $\mathrm{R} \$ 1.368,44$ & $\mathrm{R} \$ 1.457,38$ & $\mathrm{R} \$ 1.552,10$ \\
14 & $\mathrm{R} \$ 1.284,93$ & $\mathrm{R} \$ 1.368,44$ & $\mathrm{R} \$ 1.457,38$ & $\mathrm{R} \$ 1.552,10$ & $\mathrm{R} \$ 1.653,00$ \\
15 & $\mathrm{R} \$ 1.368,44$ & $\mathrm{R} \$ 1.457,38$ & $\mathrm{R} \$ 1.552,10$ & $\mathrm{R} \$ 1.653,00$ & $\mathrm{R} \$ 1.760,41$ \\
16 & $\mathrm{R} \$ 1.457,38$ & $\mathrm{R} \$ 1.552,10$ & $\mathrm{R} \$ 1.653,00$ & $\mathrm{R} \$ 1.760,41$ & $\mathrm{R} \$ 1.874,83$ \\
17 & $\mathrm{R} \$ 1.552,10$ & $\mathrm{R} \$ 1.653,00$ & $\mathrm{R} \$ 1.760,41$ & $\mathrm{R} \$ 1.874,83$ & $\mathrm{R} \$ 1.996,79$ \\
18 & $\mathrm{R} \$ 1.653,00$ & $\mathrm{R} \$ 1.760,41$ & $\mathrm{R} \$ 1.874,83$ & $\mathrm{R} \$ 1.996,79$ & $\mathrm{R} \$ 2.126,58$ \\
19 & $\mathrm{R} \$ 1.760,41$ & $\mathrm{R} \$ 1.874,83$ & $\mathrm{R} \$ 1.996,79$ & $\mathrm{R} \$ 2.126,58$ & $\mathrm{R} \$ 2.264,78$ \\
20 & $\mathrm{R} \$ 1.874,83$ & $\mathrm{R} \$ 1.996,79$ & $\mathrm{R}$ 2.126,58 & $\mathrm{R} \$ 2.264,78$ & $\mathrm{R} \$ 2.411,90$ \\
21 & $\mathrm{R} \$ 1.996,79$ & $\mathrm{R} \$ 2.126,58$ & $\mathrm{R} \$ 2.264,78$ & $\mathrm{R} \$ 2.411,90$ & $\mathrm{R} \$ 2.568,75$ \\
\hline
\end{tabular}

Fonte: Anexo Único do Decreto n. 51.526/2010 (SÃO PAULO, 2010a).

A cada jornada de trabalho do professor corresponde uma tabela de padrão de vencimento. Contudo, o valor da remuneração guarda relação direta com o número de horas de cada jornada, como ilustra a TAB. 5:

TABELA 5

Tipo de jornada, padrão de vencimento e proporção entre as jornadas

\begin{tabular}{c|c|c|c|c}
\hline Jornada & $\begin{array}{c}\text { Início da tabela } \\
\text { QPE 11A }\end{array}$ & $\begin{array}{c}\text { Final da tabela } \\
\text { QPE 11A }\end{array}$ & $\begin{array}{c}\text { Número de } \\
\text { Horas/aulas }\end{array}$ & $\begin{array}{c}\text { Proporção referente } \\
\text { a menor jornada JB }\end{array}$ \\
\hline JB & $\mathrm{R} \$ 709,10$ & $\mathrm{R} \$ 1.712,45$ & 20 & $100 \%$ \\
$\mathrm{JBD}$ & $\mathrm{R} \$ 1.63,69$ & $\mathrm{R} \$ 2.568,75$ & 30 & $150 \%$ \\
$\mathrm{~J} 30$ & $\mathrm{R} \$ 1.418,22$ & $\mathrm{R} \$ 3.424,93$ & $40^{*}$ & $200 \%$ \\
JEIF & $\mathrm{R} \$ 1.418,22$ & $\mathrm{R} \$ 3.424,93$ & 40 & $200 \%$ \\
\hline
\end{tabular}

Fonte: Anexo Único do Decreto n. 51.526/2010 (SÃO PAULO, 2010a).

Nota: A Jornada (J30) não é constituída por horas aula (45 min.), mas por hora relógio (60 min.). Para efeito de cálculo, a transformamos em horas aula. 
Em consonância com o art. 67 da LDB/96, que define a necessidade de previsão de piso salarial nos planos de carreira (BRASIL, 1996), a Lei n. 14.660/2007 apresenta o piso salarial profissional como forma de valorização do magistério. O art. 100 dessa Lei define que o piso salarial "será fixado anualmente, no mês de maio, em negociação coletiva, que será submetida à aprovação da Câmara Municipal" e "será reajustado de acordo com a legislação que rege os reajustes salariais dos servidores municipais" (SÃO PAULO, 2007).

Anteriormente à aprovação do plano de carreira pela Lei n. 14.660/2007), em 29 de novembro de 2006, foi aprovada a Lei n. 14.244, resultante de projeto do Executivo, que instituiu um conjunto de gratificações e o Abono Complementar. O Abono Complementar criou um Limite Fixado, calculado pela formula: $\mathrm{AC}=\mathrm{LF}-(\mathrm{PV}+$ $\mathrm{G})$, onde: "AC" corresponde a Abono Complementar; "LF" = Limite Fixado; PV = Padrão de Vencimento; e "G" = Gratificação de Regência, de forma que nenhum professor tivesse vencimentos inferiores ao Limite Fixado, podendo ser entendido como o estabelecimento de um piso salarial (SÃO PAULO, 2006).

A Lei n. 14.244/ 2006 previa que o Abono Complementar existiria até a reestruturação da carreira do Magistério Municipal. Contudo, mesmo após a aprovação do novo plano de carreira, o complemento para se atingir o Limite Fixado permaneceu.

Em 3 de abril de 2008, foi aprovada a Lei n. 14.709 que dispõe sobre reajuste nas Escalas de Padrões de Vencimentos e sobre a incorporação das gratificações e do Abono Complementar. Essa Lei reajustou a Escala de Padrões de Vencimentos em 37,5\%, sendo concedidos $20 \%$ em maio de 2008 e mais duas parcelas de $8,75 \%$, a primeira, em maio de 2009 e a segunda, em maio de 2010 (SÃO PAULO, 2008b). Na medida em que a tabela fosse sendo reajustada, as gratificações e o Abono Complementar seriam incorporados e extintos. Contudo, ao final da aplicação dos reajustes concedidos, o Limite Fixado pela Lei n. 14.709/2008 ainda era superior ao Padrão de Vencimentos para os professores que estavam nas primeiras posições da carreira. A TAB. 6 mostra isto: 
TABELA 6

Padrão de Vencimentos e Limite Fixado para as jornadas de trabalho

\begin{tabular}{|c|c|c|c|c|c|c|}
\hline \multirow[b]{2}{*}{ Categoria } & \multicolumn{2}{|c|}{$\begin{array}{c}\text { Jornada de } \\
20 \text { horas/aula }\end{array}$} & \multicolumn{2}{|c|}{$\begin{array}{c}\text { Jornada de } \\
20 \text { horas/aula }\end{array}$} & \multicolumn{2}{|c|}{$\begin{array}{c}\text { Jornada de } \\
40 \text { horas/aula }\end{array}$} \\
\hline & $\begin{array}{c}\text { Padrão de } \\
\text { Vencimentos } \\
\text { na } 1^{\circ} \text { posição } \\
\text { da carreira }\end{array}$ & $\begin{array}{l}\text { Limite } \\
\text { fixado }\end{array}$ & $\begin{array}{c}\text { Padrão de } \\
\text { Vencimentos } \\
\text { na } 1^{0} \text { posição } \\
\text { da carreira }\end{array}$ & $\begin{array}{l}\text { Limite } \\
\text { fixado }\end{array}$ & $\begin{array}{c}\text { Padrão de } \\
\text { Vencimentos } \\
\text { na } 1^{\circ} \text { posição } \\
\text { da carreira }\end{array}$ & $\begin{array}{l}\text { Limite } \\
\text { fixado }\end{array}$ \\
\hline 1 & 709,1 & 750 & 1063,69 & 1100 & 1418,22 & 1450 \\
\hline 2 & 804,29 & 850 & 1206,5 & 1250 & 1608,6 & 1650 \\
\hline 3 & 856,63 & 1000 & 1284,93 & 1475 & 1713,25 & 1950 \\
\hline
\end{tabular}

Fonte: Tabela elaborada pelos autores com base nas Leis n. 14.244/2006 e n. $14.709 / 2008$.

Assim, a extinção do Abono Complementar, em 2010, conforme previsto em Lei, significaria redução da remuneração para uma parte dos professores. Diante disso, o Sindicato dos Profissionais em Educação no Ensino Municipal de São Paulo (Sinpeem), o maior sindicato que representa os trabalhadores da educação da rede municipal, na campanha salarial de 2010, defendeu como um dos itens da pauta de reivindicações a "aplicação de $34 \%$ sobre os padrões de vencimentos, a título de incorporação das gratificações criadas em 2006, reposição e aumento real de salários" (SINDICATO DOS PROFISSIONAIS EM EDUCAÇÃO NO ENSINO MUNICIPAL DE SÃO PAULO, 2010) O governo propôs um reajuste de $28,41 \%$, em três parcelas, sendo a primeira em 2011, e aumento do piso. No Protocolo de Negociação - Educação foi apresentado, pela primeira vez, o termo "Valor do Piso" associado ao Limite Fixado, critério de concessão do Abono Complementar (SÃO PAULO, 2010b). Na TAB. 7 são apresentados os valores do piso para cada jornada de trabalho de acordo com a categoria: 
TABELA 7

Piso proposto no Protocolo de acordo com a jornada de trabalho

\begin{tabular}{c|c|c|c}
\hline & \multicolumn{3}{|c}{ Piso proposto no Protocolo } \\
\hline Categoria & $\begin{array}{c}\text { Jornada de 20 } \\
\text { horas/aula }\end{array}$ & $\begin{array}{c}\text { Jornada de 30 } \\
\text { horas/aula }\end{array}$ & $\begin{array}{c}\text { Jornada de 40 } \\
\text { horas/aula }\end{array}$ \\
\hline 1 & 910,56 & $1.365,84$ & $1.821,12$ \\
2 & $1.032,72$ & $1.549,08$ & $2.065,60$ \\
3 & $1.099,92$ & $1.649,88$ & $2.200,00$ \\
\hline
\end{tabular}

Fonte: Tabela elaborada pelos autores com base nos Protocolo de Negociação de 2010.

Contudo, em 25 de junho de 2010, foi aprovada uma nova Lei - a de n. 15.215-, que dispôs sobre o reajuste na Escala de Padrões de Vencimentos e que alterou a Lei do Abono Complementar e estabeleceu um índice de reajuste $(33,79 \%$, em três parcelas, a partir de 2011) e um Limite Fixado maior que o constante no Protocolo de Negociação (SÃO PAULO, 2010c), conforme conta na TAB. 8:

TABELA 8

Limite Fixado para cada jornada de trabalho (2010)

\begin{tabular}{c|c|c|c}
\hline & \multicolumn{3}{|c}{ Limite Fixado } \\
\hline Categoria & $\begin{array}{c}\text { Jornada de 20 } \\
\text { horas/aula }\end{array}$ & $\begin{array}{c}\text { Jornada de 30 } \\
\text { horas/aula }\end{array}$ & $\begin{array}{c}\text { Jornada de 40 } \\
\text { horas/aula }\end{array}$ \\
\hline 1 & 948,70 & $1.423,11$ & $1.897,44$ \\
2 & $1.076,05$ & $1.614,17$ & $2.152,26$ \\
3 & $1.146,09$ & $1.719,12$ & $2.292,17$ \\
\hline
\end{tabular}

Fonte: Tabela elaborada pelos autores com base na Lei n. 15.215/10

Além do vencimento fixado para cada jornada de trabalho e vantagens pecuniárias permanentes decorrentes da evolução funcional e da promoção, os professores recebem quinquênios, conforme estabelecido no Estatuto dos Funcionários Públicos do Município de São Paulo. A Lei estabelece que a cada período de cinco anos, contínuos ou não, o funcionário receba adicional por tempo de serviço público municipal: 
de 5 a 10 anos - 5\%; de 10 a 15 anos - 10,25\%; de 15 a 20 anos - 15,76; de 20 a 25 anos - $21,55 \%$; de 25 a 30 anos - 27,63\%; de 30 a 35 anos - 34,01\%; mais de 35 anos - 40,71\%. O adicional é calculado sobre o padrão do cargo que o funcionário estiver exercendo e não é cumulativo. Conforme o art. 114 do Estatuto, o adicional por tempo de serviço é incorporado à remuneração (SÃO PAULO, 1979).

Outro elemento de remuneração vinculado ao tempo de serviço prestado é a Sexta Parte, também prevista no Estatuto dos Funcionários Públicos do Município de São Paulo. A Lei Orgânica do Município de São Paulo (1990) reduziu o tempo de 25 para 20 anos de efetivo exercício no serviço público municipal para o servidor ter direito a receber a Sexta Parte que, como o nome diz, será concedido, mensalmente, 1/6 dos vencimentos a cada professor que completar 20 anos de exercício, sem alterar o salário base, mas como gratificação especial, assim identificada nos demonstrativos de pagamento. Além das vantagens pecuniárias permanentes e incorporadas à remuneração para efeitos de aposentadoria, os professores recebem gratificações e adicionais concedidos por tempo determinado, de acordo com especificações próprias.

O Prêmio de Desempenho Educacional (PDE), criado pela Lei n. 14.938/2009, é concedido anualmente aos servidores lotados e em efetivo exercício nas unidades da Secretaria Municipal de Educação. Essa gratificação não tem natureza de remuneração não sendo considerada para o cálculo de décimo terceiro, de férias e de aposentadoria. A Lei estabelece que a gratificação seja atribuída em razão da avaliação de desempenho das escolas. Para ter direito ao PDE o servidor deve ter iniciado exercício até 31 de maio do ano corrente e ter, no mínimo, seis meses de efetivo exercício nas escolas (SÃO PAULO, 2009).

Essa Lei prevê que os valores estabelecidos anualmente serão calculados considerando-se o tempo de exercício no cargo ou função e as diretrizes do Sistema de Avaliação Institucional da Educação Municipal. Contudo, esse sistema de avaliação, previsto no Plano de Carreira, ainda não foi regulamentado. Diante disso, o governo estabeleceu critérios (faltas e licença médica) para o pagamento da gratificação, sempre na proporcionalidade de $50 \%$ para JB (20 horas/aulas), 75\% para JBD (30 horas/aulas) e $100 \%$ 
para JEIF, J40 e J30 (40 horas/aulas) do valor máximo do Prêmio. Em 2010, esse valor foi de R\$2.400,00. O PDE foi pago em duas parcelas: uma, em junho do ano corrente e a segunda, em janeiro do ano seguinte.

O atual plano de carreira prevê a Gratificação por Local de Trabalho (GLT), para os profissionais da educação que trabalham em unidade escolar que sofra "interferências da conjuntura socioambiental", como dificuldade de lotação de profissionais e baixo Índice de Desenvolvimento Humano (IDH). A Lei estabelece que o valor corresponda a 15\% da referência QPE11A, na Jornada Básica do Docente (SÃO PAULO, 2007). A Gratificação por Local de Trabalho (GLT) não pode ser acumulada com a Gratificação de Difícil Acesso (GDA), criada pela Lei n. 11.035/1991. Contudo, a GLT necessita de regulamentação, o que ainda não ocorreu, estando em vigor somente a GDA, que é calculada sobre o padrão correspondente à classe inicial da respectiva carreira. Os percentuais são de $30 \%$ e de $50 \%$ a depender da localização da escola na qual o professor trabalha.

Aos professores que lecionam no período noturno, das 19:00 às 23:00, os arts. 63, 64 e 65 do Plano de Carreira estabelecem que deve ser pago o valor da respectiva hora aula ou hora trabalho acrescida de $30 \%$, sendo contabilizado, também, proporcionalmente, nos descansos semanais, feriados, dias de ponto facultativo, férias, recesso escolar e demais licenças e afastamentos remunerados (SÃO PAULO, 2007). O adicional noturno não se configura como remuneração, mas faz parte do cálculo para contribuição previdenciária.

Todos os servidores municipais cuja renda bruta mensal não ultrapassar o equivalente a cinco salários mínimos ${ }^{15}$ têm direito ao valealimentação. O valor do vale-alimentação, quando foi instituído pela Lei n. 14.588/2007, era de R\$190,00. A Lei prevê atualização anual do valor pelo IPC/FIPE. O pagamento do vale-alimentação, de acordo com a Lei, deve ser feito por meio de cartão magnético ou outra forma assemelhada, para uso exclusivo na compra de mercadorias alimentícias. Como não houve regulamentação, o auxílio está sendo pago em pecúnia. O vale-

15 A Lei n. 14.588/2007 define salário bruto mensal como "a soma de todos os valores a que fazem jus os servidores como parte de seus vencimentos mensais, excluindo-se apenas os pagos a título de auxílio-transporte, auxílio-refeição, 1/3 (um terço) de férias, abono de permanência e vantagens indenizatórias ou eventuais". 
alimentação não possui natureza remuneratória.

Aos servidores também é pago o auxílio-refeição, instituído pela Lei n. 12.858/1999, sendo seu valor, em 2010, de R $\$ 11,54$ / dia. O professor em JB (20 horas aula) não faz jus ao auxílio-refeição.

\section{Considerações Finais}

A análise do plano de carreira dos profissionais da educação municipal de São Paulo, nos aspectos referentes à forma de ingresso, à composição da jornada de trabalho, à progressão e à composição da remuneração permite afirmar que, em linhas essenciais, eles foram contemplados de maneira digna, na legislação.

Dentre esses aspectos, destacamos a existência de uma jornada de trabalho que possui $1 / 3$ de sua totalidade reservada a atividades de formação, de preparação das aulas e de trabalho coletivo. No entanto, o fato dessa composição não se aplicar a todas as jornadas previstas no plano de carreira limita as possibilidades dos professores contarem com tempo destinado a atividades pedagógicas que são realizadas extraclasse. Essa medida vem se tornando comum em parte significativa das jornadas adotadas, pois, apesar de manter a aparência de atendimento à complexidade da atividade docente, permite a adoção de formas indignas de trabalho no magistério, em especial as que excluem ou reduzem significativamente as indispensáveis horas de trabalho coletivo na escola.

Soma-se a isso a possibilidade de, por meio de acúmulo de cargo ou jornada complementar de trabalho, o professor poder trabalhar até 70 horas semanais, anulando a reivindicação histórica de uma jornada compatível com a especificidade do trabalho docente.

É verdade que essa realidade não é específica do magistério da cidade de São Paulo, estando presente em todo o país. No entanto, o fato da CF/88 estabelecer a jornada máxima de 40 horas, para os funcionários públicos, parece não incomodar os dirigentes educacionais que têm adotado, até em textos legais, jornadas de trabalho com limites superiores. Veja-se, como exemplo, o art. 19 da Lei n. 14.660/2007, em clara desobediência à $\mathrm{CF} / 88$. Aquele artigo dispõe textualmente: “Em regime de acúmulo de 
cargos, inclusive em outros entes federativos, o profissional de educação não poderá exceder a carga horária de trabalho semanal de 70 (setenta) horas." (SÃO PAULO, 2007, grifo nosso). Ou seja, se ele não pode exceder, significa que ele pode cumprir até 70 horas semanais de trabalho.

Em relação à dispersão salarial, estimada em até 100\%, pode-se dizer que está em consonância com as discussões atuais sobre carreiras do magistério. Embora essa dispersão possa significar um salário inicial mais baixo, considerando-se o montante de recursos aplicados, é atrativa, na medida em que o professor tem expectativa de melhores salários no decorrer do tempo de serviço.

No entanto, constatou-se que em nenhum ato legal do município foi proposto, sequer experimentalmente, aos professores e especialistas da educação, uma jornada de trabalho em Regime de Dedicação Exclusiva (RDE), com aumento do salário vigente entre 80 e $120 \%$, como acontece com outras carreiras públicas ou mesmo no magistério da educação superior.

Um aspecto positivo constatado em relação ao magistério paulista é o número surpreendentemente alto de professores efetivos da rede municipal, situação destoante do resto do país, uma vez que somente cerca de 50\% dos professores das diferentes redes públicas são efetivos.

Em relação à composição da remuneração, pode-se destacar o fato do piso profissional dos professores da rede municipal de São Paulo ser superior ao piso profissional nacional, correspondendo, em 2010, a $\mathrm{R} \$ 1.450,00$ para uma jornada de 30 horas (40 horas/aula) do professor com formação em nível médio, e R \$1.950,00 pela mesma jornada para o professor com Licenciatura Plena. O piso nacional profissional mínimo, em 2010, foi de $\mathrm{R} \$ 1.312,85$ pela jornada de 40 horas semanais de trabalho, para o professor com formação em nível médio. No entanto, dado o fato de se tratar do Estado e da Cidade mais ricos do país e com um dos mais altos custos de vida, a diferença de valor no piso é pouco significativa, podendo-se afirmar que não se trata de um piso salarial que se destaque, no país, como exemplo de valorização do magistério.

Assim, pode-se dizer que a remuneração do professor da rede municipal só é mais atrativa por conta da progressão na carreira (progressão e evolução) e dos quinquênios e sexta parte que são 
incorporados para efeitos de aposentadoria, não se desconsiderando as diferentes gratificações que lhe são concedidas.

O PDE é um bom exemplo, pois, por se tratar de um prêmio, compõe a remuneração de maneira pontual, não fazendo parte permanente da carreira. Reflete uma dinâmica atual de introduzir prêmios e gratificações em detrimento de aumentos no salário base e de componentes permanentes da carreira para serem incorporados à aposentadoria. As gratificações de difícil acesso, por local de trabalho e de adicional noturno constituem parte da remuneração de uma parte dos professores, na medida em que se destinam a situações de trabalho específicas. $\mathrm{O}$ vale-alimentação, destinado a uma parte dos servidores municipais e o auxílio-refeição pago a todos os professores, também, compõem a remuneração como auxílio para fins específicos.

O plano de carreira do quadro de docentes da rede municipal da cidade de São Paulo, nos aspectos analisados, contempla, em grande medida, a preocupação de uma progressão funcional atrativa aos ingressantes, com a ponderação necessária de que a avaliação de desempenho ainda não faz parte dos critérios atuais de evolução funcional, ainda que "Certificados de Valoração Profissional" estejam previstos nos arts. 35, 38 e 40 da Lei n. 14.660/ 2007. Dado que a avaliação de desempenho é um item presente em praticamente toda a legislação referente aos planos de carreira do magistério do país é mister o aprofundamento teórico e prático sobre as relações entre valorização profissional, avaliação de desempenho e melhoria da qualidade do ensino.

Para Morduchowicz (2003), no caso de São Paulo, trata-se de uma carreira calcada em concepções tradicionais, na medida em que a progressão está baseada, principalmente, no tempo de serviço e na titulação e não na avaliação de desempenho, considerada mais "moderna" e adequada para mensurar a dedicação e a competência dos professores, conforme defendido por alguns autores (ABREU; BALZANO, 2001).

No entanto, apesar da pouca discussão sobre a repercussão desse novo entendimento sobre as relações profissionais dos docentes e especialistas da educação, legislações incorporando a avaliação de desempenho já 
tinham sido aprovadas, em 2010, em 14 estados brasileiros. Leis que introduziram a avaliação de desempenho profissional do docente vinculada ao desempenho dos alunos (em especial, contabilizando o número de acertos nas provas nacionais e/ou estaduais) como condição para novos ganhos salariais, sempre como "gratificações" que não se incorporam ao salário base.

O Índice de Desenvolvimento da Educação Básica (IDEB), criado pelo MEC, tem sido um dos principais motivadores para que estados e municípios adotem essa fórmula, acreditando-se constituir "motivação" aos professores para o alcance de metas estabelecidas, parte delas improváveis, quando analisadas as circunstâncias e as condições materiais do trabalho escolar e docente.

Esse tipo de avaliação tem contaminado as propostas atuais de planos de carreira e de estatutos do magistério, trazendo o critério da "competição" entre pares e da meritocracia como importante fator de motivação para uma atuação docente mais criativa, dinâmica e atualizada. Na nova fórmula, substitui-se a isonomia salarial que, historicamente, fundamentou o trabalho coletivo como condição de sucesso de uma escola e de uma equipe de professores e especialistas, por uma competição entre pares, na qual quem se destaca dos outros deve ser premiado para continuar "motivado" a se dedicar. Em compensação, aos "acomodados", o mínimo da remuneração deve ser mantido para que eles "percebam" que, se quiserem ganhar mais, terão que se dedicar mais e sempre.

Mesmo que os (poucos) estudos realizados, de forma independente, mostrem que essa nova fórmula: $>$ salário $=>$ produtividade $=>$ qualidade de ensino não tem suporte na realidade escolar, a mídia e os empresários, que vêm atuando cada vez mais no ambiente educacional, insistem em estabelecer, como critério para sua "cooperação", esta equação para garantir, à semelhança de suas empresas, o sucesso do produto "educação pública cidadã" no input professor competente + salários melhores $=$ melhor resultados nas provas nacionais e estaduais.

O momento é de atenção e resistência, pois, se os sindicatos municipais não tiverem uma atuação política competente para "brecar" esse 
processo, em breve poder-se-á discutir em São Paulo se os "Certificados de Valoração Profissional" não terão se transformado no principal critério para evolução funcional do magistério paulistano.

Diante disso, ficam os seguintes questionamentos: poderá um processo de monitoramento das unidades de ensino garantir, ao mesmo tempo, a melhoria da qualidade de ensino, a valorização dos Profissionais da Educação e a eficiência institucional, como pretende a legislação municipal? Ou trata-se de artifícios para que a competitividade, e não mais a solidariedade, dirija as ações e projetos educacionais nas escolas públicas? Interessam, aliás, projetos pedagógicos diferenciados em cada uma das escolas públicas ou a uniformidade e sua implementação é que definirão o critério da excelência? 


\section{Referências}

ABREU, Mariza Vasques de; BALZANO, Sônia. Progressão na carreira do magistério e avaliação de desempenho. In: RODRIGUES, Maristela Marques; GIÁGIO, Mônica (Orgs.). Guia de Consulta para o Programa de Apoio aos Secretários Municipais de Educação - PRASEM III. Brasília: FUNDESCOLA/MEC, 2001.

BRASIL. Constituição (1988). Constituição da Republica Federativa do Brasil. Brasília, DF: Senado Federal, 1988.

. Emenda Constitucional n. 14 de 12 de setembro de 1996.

Modifica os arts. 34, 208, 211 e 212 da Constituição Federal e dá nova redação ao art. 60 do Ato das Disposições constitucionais Transitórias. Brasília, 1996.

. Lei n. 9.394 de 20 de dezembro de 1996. Estabelece as Diretrizes e Bases da Educação Nacional. Brasília, 1996.

. Lei n. 9.424 de 24 de dezembro de 1996. Dispõe sobre o Fundo de Manutenção e Desenvolvimento do Ensino Fundamental e Valorização do Magistério, na forma prevista no art. 60, § $7^{\circ}$ do Ato das Disposições Constitucionais Transitórias e dá outras providências. Brasília, 1996.

. Emenda Constitucional n. 19 de 4 de junho de 1998. Modifica o regime e dispõe sobre princípios e normas da Administração Pública, servidores e agentes políticos, controle de despesas e finanças públicas e custeio de atividades a cargo do Distrito Federal, e dá outras providências. Brasília, 1998.

. Lei n. 11.738 de 16 de julho de 2008. Regulamenta a alínea " $\mathrm{e}$ " do inciso III do caput do art. 60 do Ato das Disposições Constitucionais Transitórias, para instituir o piso salarial profissional 
nacional para os profissionais do magistério público da educação básica. Brasília, 2008.

. Ministério da Educação. Conselho Nacional de Educação. Parecer CNE/CEB n. 9/2009 aprovado em 2 de abril de 2009. Revisão da Resolução CNE/CEB n. 3/97, que fixa Diretrizes para os novos Planos de Carreira e de Remuneração para o Magistério dos Estados, do Distrito Federal e dos Municípios. Brasília, 2009.

Ministério da Educação. Conselho Nacional de Educação Resolução CNE/CEB n. 2 de 28 de maio de 2009. Fixa as Diretrizes Nacionais para os Planos de Carreira e Remuneração dos Profissionais do Magistério da Educação Básica Pública, em conformidade com o artigo $6^{\circ}$ da Lei ${ }^{0} 11.738$, de 16 de julho de 2008, e com base nos artigos 206 e 211 da Constituição Federal, nos artigos $8^{\circ}$, § $1^{\circ}$, e 67 da Lei $n^{\circ} 9.394$, de 20 de dezembro de 1996, e no artigo 40 da Lei $n^{\circ}$ 11.494, de 20 de junho de 2007. Brasília, 2009.

DUTRA JÚNIOR et al. Plano de carreira e remuneração do magistério público: LDB, FUNDEF, Diretrizes nacionais e nova concepção de carreira. Brasília: FUNDESCOLA/MEC, 2000.

GATTI, Bernadete Angelina; BARRETO, Elba Siqueira de Sá. Professores do Brasil: impasses e desafios. Brasília: UNESCO, 2009.

MONLEVADE, João Antonio Cabral de. Valorização salarial dos professores: o papel do Piso Salarial Profissional Nacional como instrumento de valorização dos professores da educação básica pública. 2000. Tese (Doutorado em Educação). Faculdade de Educação, Universidade Estadual de Campinas, Campinas, 2000.

MORDUCHOWICZ, Alejandro. Carreiras, incentivos e estruturas salariais docentes. Rio de Janeiro: PREAL Brasil, 2003. 
SÃO PAULO. Prefeitura Municipal. Lei n. 8.989 de 29 de outubro de 1979. Dispõe sobre o Estatuto dos Funcionários Públicos do Município de São Paulo e dá providências correlatas. São Paulo, 1979.

. Prefeitura Municipal. Lei Orgânica do Município de São Paulo de 4 de abril de 1990. São Paulo, 1990, com as alterações introduzidas até 2010. São Paulo, 1990.

. Prefeitura Municipal. Lei n. 11.035 de 11 de julho de 1991. Institui a Gratificação de Difícil Acesso, prevista no artigo 95 da Lei Orgânica do Município de São Paulo, e dá outras providências. São Paulo, 1991.

. Prefeitura Municipal. Lei n. 11.229 de 26 de junho de 1992. Dispõe sobre o estatuto do magistério Público Municipal, e dá outras providências. São Paulo, 1992.

. Prefeitura Municipal. Lei n. 11.434 de 12 de novembro de 1993. Dispõe sobre a organização dos Quadros dos Profissionais de Educação, da Prefeitura do Município de São Paulo, e dá outras providências. São Paulo, 1993.

. Prefeitura Municipal. Lei n. 12.858 de 18 de junho de 1999. Institui o Auxílio-Refeição, nas condições que específica, e dá outras providências. São Paulo, 1999.

Prefeitura Municipal. Lei n. 14.244 de 29 de novembro de 2006. Institui a Gratificação de Regência, a Gratificação de Atividade Educativa, a Gratificação de Apoio Educacional, a Gratificação de Atribuição Educacional, a Gratificação Especial para Especialistas, a Gratificação de Apoio à Educação, a Gratificação por Desenvolvimento Sócio-Educativo e o Abono Complementar, a serem concedidos aos servidores que especifica. São Paulo, 2006. 
. Prefeitura Municipal. Lei n. 14.588 de 12 de novembro de 2007. Altera a redação dos art. $1^{\circ}$ ao $6^{\circ}$ da Lei Municipal $n^{\circ} 13.598 / 03$ e institui o Vale-Alimentação, benefício a ser concedido aos servidores municipais que especifica. São Paulo, 2007.

. Prefeitura Municipal. Lei n. 14.660 de 26 de dezembro de 2007. Dispõe sobre alterações das Leis $n^{0} 11.229$, de 26 de junho de 1992, nº 11.434, de 12 de novembro de 1993 e legislação subsequente, reorganiza o Quadro dos Profissionais de Educação, com as respectivas carreiras, criado pela Lei n ${ }^{0} 11.434$, de 1993, e consolida o Estatuto dos Profissionais da Educação Municipal. São Paulo, 2007.

. Prefeitura Municipal. Secretaria Municipal de Educação. Portaria n. 1.566 de 17 de setembro d 2008. Dispõe sobre Projetos Especiais de Ação - PEAs e dá outras providências. São Paulo, 2008a.

. Prefeitura Municipal. Lei n. 14.709 de 3 de abril de 2008.

Dispõe sobre o reajustamento das Escalas de Padrões de Vencimentos dos Quadros dos Profissionais de Educação, a absorção das gratificações instituídas pela Lei $n^{0}$ 14.244, de 29 de novembro de 2006, na forma que especifica e introduz alterações na Lei $\mathrm{n}^{\circ} 14.660$, de 26 de dezembro de 2007. São Paulo, 2008b.

. Prefeitura Municipal. Lei n. 14.938 de 30 de junho de 2009. Institui o Prêmio de Desempenho Educacional e revoga as leis e os dispositivos legais que especifica. São Paulo, 2009.

. Prefeitura Municipal. Decreto n. 51.526 de 29 de maio de 2010. Dispõe sobre o reajustamento das escalas de padrões de vencimentos dos Quadros dos Profissionais de Educação (QPE), nos termos do disposto no artigo $1^{\circ}$ da Lei ${ }^{0}$ 14.709, de 3 de abril de 2008. São Paulo, 2010a. 
de 03 de junho de 2010. Diário Oficial da Cidade de São Paulo, p. 63, São Paulo, 2010a.

Prefeitura Municipal. Lei n. 15.215 de 25 de junho de 2010.

Dispõe sobre o reajustamento das Escalas de Padrões de Vencimentos do Quadro dos Profissionais da Educação, mantém a concessão do Abono Complementar que especifica e introduz alterações na Lei ${ }^{\circ}$ 14.244, de 29 de novembro de 2006; reconfigura a carreira de Agente Escolar, do Quadro de Apoio à Educação, do Quadro dos Profissionais da Educação, prevista na Lei n 14.660 , de 26 de dezembro de 2007, e legislação subsequente. São Paulo, 2010c.

SINDICATO DOS PROFISSIONAIS EM EDUCAÇÃO NO ENSINO MUNICIPAL DE SÃO PAULO (Sinpeem). Jornal do Sindicato, n. 172, 2010. 


\title{
Teacher's work and a enhancement of teaching in the public educational system of São Paulo
}

\begin{abstract}
Since 1990s, Brazilian states and municipalities have to formulate or adjust teachers' career plans and salaries according to a new set of federal laws. This movement translates, in some parcel, the incorporation of the teacher's claims for the construction of a career plan in the whole educational system and reflects an understanding that the quality of education is also linked to the career and the teachers' incomes. This paper analyzes the rules of admission, the working hours' composition, the career advancement and the composition of remuneration according the Law nr 14.660/2007 that reorganizes the Teachers' Professional Status of Education in the city of Sao Paulo.
\end{abstract}

Keywords: enhancement of teaching, career plan, teacher's workday, teacher's salary.

Recebido: 18/01/2012

Aprovado: 17/06/2012 